\title{
Chapter 12 \\ Task Design Frameworks \\ in Mathematics Education Research: \\ An Example of a Domain-Specific Frame \\ for Algebra Learning \\ with Technological Tools
}

\section{Carolyn Kieran}

\begin{abstract}
Theorizing about task design is a fairly recent area of attention within the educational research community, emerging in the late 1960s and continuing with growing interest to the present day. To reflect the evolution in task design theorization, this chapter focuses first on historical aspects and highlights the main theorizing initiatives of the past half-century. The second part offers a conceptualization of current theoretical frameworks and principles for task design within mathematics education research - a conceptualization that distinguishes among the three levels of grand, intermediate, and domain-specific frames. The third part of the chapter elaborates on the notion of domain-specific frames by presenting an example of the design features underpinning a study on the CAS-supported co-emergence of technique and theory within the activity of algebraic factorization and describes how the classroom implementation of the proving phase of the designed task-sequence was supported by the instructional practice of the teacher and by the role played by the technology as a tool to spark thinking.
\end{abstract}

Keywords Task design - Theoretical frameworks for task design • Domain-specific frames - Task design in algebra education • Design as intention • Design as implementation - Digital artifacts as tools for thinking $\cdot$ Instructional practice within the activity of proving

The historical overview in this paper is drawn partially from my contribution to a chapter (Kieran et al. 2015) in the Springer publication, Task Design in Mathematics Education (Watson and Ohtani 2015), and the domain-specific example is based on our team's past research and was featured briefly in Kieran (2017).

C. Kieran $(\bowtie)$

Département de Mathématiques, Université du Québec à Montréal, 201 avenue du

Président-Kennedy, local PK-5151, Montréal, QC H2X 3Y7, Canada

e-mail: kieran.carolyn@uqam.ca

(C) The Author(s) 2019

G. Kaiser and N. Presmeg (eds.), Compendium for Early Career

Researchers in Mathematics Education, ICME-13 Monographs,

https://doi.org/10.1007/978-3-030-15636-7_12 


\subsection{Introduction}

The field of mathematics education could be said to have been involved in design ever since its beginnings. However, as Erich Wittmann (1995) remarked, in a paper titled Mathematics Education as a Design Science, the design of teaching units was never a focus of the mathematics education research community until the mid-1970s. Michèle Artigue (2009) too has argued that "didactical design has always played an important role in the field of mathematics education, but it has not always been a major theme of theoretical interest in the community" (p. 7). The movement toward theoretically-based design research from the 1960s onward has benefitted largely from the emergence of an international research community in mathematics education, as well as from contributions from the disciplines of mathematics and psychology (Kilpatrick 1992).

To illustrate these influences and their evolution within the community, this chapter is divided as follows. The first section (Sect. 12.2) provides a brief historical overview of theorizing initiatives with respect to task design in our field over the past half-century. The second section (Sect. 12.3) presents a conceptualization of current frameworks for task design in mathematics education and describes the characteristics of the design principles offered by these frames - a conceptualization that distinguishes among the three levels of grand, intermediate, and domain-specific frames. The third section (Sect. 12.4) offers an example of a domain-specific frame developed to guide our research team's investigations into the learning of algebraic techniques and theory in an environment involving computing technology.

\subsection{Brief History of the Emergence of Design-Related Theoretical Work from the 1960s Onward}

In 1969, the first International Congress on Mathematical Education (ICME) took place in Lyon. A round table at that congress set the stage for the formation in 1976 of what was to quickly become the largest association of mathematics education researchers in the world, the International Group for the Psychology of Mathematics Education (PME). The emergence of this community was accompanied by the creation of several research journals, as well as research institutes in many countries. The late 1960 and 1970s thus signalled a huge surge and interest in research in mathematics education, leading to theorizing initiatives related to design.

\subsubsection{Influences from Psychology}

This surge in research in mathematics education had to rely almost exclusively in its early days on psychology as a source of theory (Johnson 1980). Piaget's (1971) 
cognitively-oriented, genetic epistemology was one of the main examples of psychological frames adopted by the emerging mathematics education research community in its studies on the learning of mathematics. However, it was psychologists who had an interest in education who would initiate some of the early theorizing efforts related specifically to design. For example, in 1965 Robert Gagné published The Conditions of Learning. Based on models from behaviourist psychology, Gagné's (1965) nine conditions of learning were viewed as principles for instructional design. In parallel with the instructional design approach being developed by Gagné and others, advances in design considerations were stimulated by the theorizing of the cognitive scientist and Nobel laureate, Herbert Simon (1969), in his book, The Sciences of the Artificial. Robert Glaser (1976) in his Components of a Psychology of Instruction: Toward a Science of Design distinguished between the descriptive nature of theories of learning and the prescriptive nature of theories of instruction. In integrating design considerations into instructional research, he argued that the structure of the subject-matter discipline may not be the most useful for facilitating the learning of less expert individuals - a point of view that was questioned somewhat by researchers in mathematics education. Thus, mathematics education researchers would need to develop during the years to come their own scientific approaches to designing environments for the learning of mathematics and to generating frameworks for task design in particular.

\subsubsection{Early Design Initiatives of the Mathematics Education Research Community}

During the 1970s, the focus within the emerging mathematics education research community was on the learning of mathematics and the development of models of that learning. For example, the paper that the mathematician Hans Freudenthal presented at PME3 in 1979 (one of the 24 research reports presented in 1979 at the recently formed PME) dealt with the growth of reflective thinking in learners (Freudenthal 1979). That paper sowed the seeds for a mathematical-psychological approach to task design — an approach that was to develop during the late 1980s and 1990s into the instructional theory specific to mathematics education known as Realistic Mathematics Education.

In contrast to the majority of the 1979 PME3 papers oriented toward learning, the paper by Alan Bell (1979) touched more directly upon issues related to design. While he too focused on learning, it was done through the lens of different teaching approaches with various curriculum units that had been designed for the South Nottinghamshire project. In Bell's paper, which was a forerunner of the early ways of thinking about design within the mathematics education research community, design considerations were seen more from the perspective of particular teaching methods than as approaches to the design of tasks per se. 
The 1980s brought some evolution in this regard with, for example, the work of Wittmann. In his 1984 Educational Studies in Mathematics paper (a modified version of his opening address at the 14th annual meeting of German mathematics educators in 1981), titled Teaching units as the integrating core of mathematics education, Wittmann (1984) argued for tasks displaying the following characteristics: the objectives, the materials, the mathematical problems arising from the context of the unit, and the mostly mathematical, sometimes psychological, background of the unit. He suggested that a teaching unit is not an elaborated plan for a series of lessons; rather it is an idea for a teaching approach that leaves open various ways of realizing the unit.

During the years 1985-1988, one of the PME working groups focused on establishing principles for the design of teaching. In 1988, a collection of papers from this working group was put together by the Shell Centre under the title The Design of Teaching-Papers from a PME Working Group, and subsequently published in a special issue of Educational Studies in Mathematics in 1993. In his editorial for the special issue, Bell (1993) emphasized that the principles of teaching practice should be in harmonious integration with the principles that are incorporated into the design of teaching materials - a characteristic that would continue to be important in task design within the community over the decades to come.

The 1980s in France ushered in the development of didactical engineering (Artigue 1992) — a theory-based approach to conducting research that had didactical design at its heart. However, as noted by Artigue (2009), the original designs tended to go through a certain mutation in practice, leading her to remark that "the relationships between theory and practice as regards didactical design are not under theoretical control" (p. 12). This awareness pointed to one of the inherent limitations in theorizing about task design in isolation from considerations regarding instructional practice.

\subsubsection{The 1990s and Early 2000s: Development of Design Experiments}

The term design experiment came into prominence in the 1990s with the psychologist Ann Brown's (1992) publication on educational design. Several factors had fallen into place, including the maturing of the mathematics education research community over a 20-year period and an evolving desire to be able to study within one's research not just learning or not just teaching (Lesh 2002). Design experiments aimed at taking into account the entire learning picture. As Cobb et al. (2003) pointed out: "Design experiments ideally result in greater understanding of a learning ecology. ... Elements of a learning ecology typically include the tasks or problems that students are asked to solve, the kinds of discourse that are encouraged, the norms of participation that are established, the tools and related material means provided, and the practical means by which classroom teachers can 
orchestrate relations among these elements" (p. 9). Within this conception of design experiments, the task or task-sequence is but one of a larger set of design considerations involving the entire learning ecology. ${ }^{1}$

\subsubsection{From Early 2000 Onward}

Theorizing related to design in mathematics education research developed considerably during the 2000s (Kelly et al. 2008). Contributing to this development was the recommendation put forward by Cobb et al. (2003):

General philosophical orientations to educational matters-such as constructivism - are important to educational practice, but they often fail to provide detailed guidance in organizing instruction. The critical question that must be asked is whether the theory informs prospective design and, if so, in precisely what way? Rather than grand theories of learning that may be difficult to project into particular circumstances, design experiments tend to emphasize an intermediate theoretical scope. (pp. 10-11)

Cobb et al. also argued that design experiments are conducted to develop theories, not merely to tune empirically 'what works': "a design theory explains why designs work and suggests how they may be adapted to new circumstances" (p. 9).

In addition to the evolution in theoretical perspectives on design during these years, the term task design came to be more clearly present in discussions of research related to design. For example, at the 2005 PME conference, a research forum was dedicated to task design for the first time and had as its stated theme, "The significance of task design in mathematics education" (Ainley and Pratt 2005). At ICME-11 in 2008 the scientific program committee initiated the idea of having a Topic Study Group (TSG) on task design: "Research and development in task design and analysis". The excitement generated regarding this research area was such that a similar TSG was put on the program for ICME-12 in 2012, as well as for ICME-13 in 2016 and for ICME-14 in 2020. This interest was further illustrated by the holding of the 2013 ICMI Study-22 Conference on the same theme.

\subsubsection{A Key Issue}

In closing this section on the historical overview of the emergence of theorizing research related to design activity, I want to draw attention to an issue that is central to the complex role of theory as both a resource for and a product of design

\footnotetext{
${ }^{1}$ The term task (or task-sequence, which could take an entire lesson, or more) is characterized in the ICMI Study-22 Discussion Document as "anything that a teacher uses to demonstrate mathematics, to pursue interactively with students, or to ask students to do something ... also anything that students decide to do for themselves in a particular situation" (Watson et al. 2013, p. 10).
} 
research. It involves the terms design as intention and design as implementation. In a paper on design tools in didactical research, Ruthven et al. (2009) expanded upon the distinction between design as intention and design as implementation (Collins et al. 2004). Design as implementation focuses attention on the process by which a designed sequence is integrated into the classroom environment and subsequently is progressively refined, whereas design as intention addresses specifically the initial formulation of the design. While many studies address both, the distinction can be useful for understanding certain nuanced differences between one study and another. Ruthven et al. (2009) state that design as intention emphasizes the "original design and the clarity and coherence of the intentions it expresses" (p. 329). The provision for this clarity and coherence is generally achieved by the use of theoretical frames that are already well developed.

In contrast to the front-end importance given to theory-based design tools by Ruthven et al. (2009), Gravemeijer and Cobb (2006) put the focus more toward the development of theory and its role as a product of the design research. In their design-experiment studies, the initial theoretical base for the study, and its accompanying instructional plan, undergo successive refinements by means of the implementation process. The description of the entire process constitutes the development of the theory. Because of the centrality of the implementation process in the development of the resulting theory, such studies are characterized as design as implementation studies, even though they also have a strong initial theoretical base. The complexity of the dialectical role played by theory in such research warns, however, against equating, on the one hand, design as intention and theory as a resource or, on the other hand, design as implementation and theory as a product.

Put another way, theories are both a resource and a product. As a resource, they provide theoretical tools and principles to support the design of a teaching sequence (e.g., Ruthven et al. 2009) and, as a product of design research, theories inform us about both the processes of learning and the means that have been shown to support that learning (Cobb et al. 2003). In practice, most design experiments combine both orientations: the design is based on a conceptual framework and upon theoretical propositions, while the successive iterations of implementation and retrospective analysis contribute to further theory building that is central to the research.

\subsection{A Conceptualization of Current Theoretical Frameworks and Principles for Task Design in Mathematics Education Research}

\subsubsection{Introduction}

The historical look at the early research efforts related to theorizing about task design hinted at a mix of task and instructional considerations. However, the extent 
to which instructional aspects are factored into task design is but one of the ways in which design frameworks can vary. Frameworks can also differ according to the manner in which they draw upon cognitive, sociological, sociocultural, discursive, or other theories. In addition, frameworks are distinguishable according to their relation to various task genres, that is, whether the tasks are geared toward (i) the development of mathematical knowledge (such as concepts, procedures, representations), (ii) the development of the processes of mathematical reasoning (such as conjecturing, generalizing, proving, as well as fostering creativity, argumentation, and critical thinking), (iii) the development of modelling and problem-solving activity, (iv) the assessment of mathematical knowledge, processes, and problem solving, and so on.

As well, some frameworks may be more suited to the design of specific tasks; others to the design of lesson flow; still others to the design of sequences involving the integration of particular artefacts. Because several considerations enter into an overall design - considerations that include the specific genre of the task, its instructional support, the classroom milieu, the tools being used, and so on-each part of the design might call for different theoretical underpinnings. Thus, the resulting design can involve a networking of various theoretical frames and principles (Prediger et al. 2008).

A more holistic way of thinking about frames is elaborated immediately below. It involves conceptualizing them in terms of three different levels, that is, grand frames, intermediate level frames, and domain-specific frames-all of these levels of frames together constituting the theoretical base for the design of a given study.

\subsubsection{Grand Theoretical Frames}

Mathematics education research has tended in large measure to adopt such grand theoretical perspectives as the cognitive-psychological, the constructivist, the socio-constructivist, and the sociocultural. However, as pointed out by Lerman et al. (2002), these are but four from the vast array of theoretical fields, in addition to those from educational psychology and/or mathematics, that have back-grounded mathematics education research. In line with Cobb (2007), who argued that such grand theories need to be adapted and interpreted in order to serve the needs of design research, and the fact that these grand theories have already been well described in the literature, I now address the less well-documented levels of intermediate and domain-specific design frames.

\subsubsection{Intermediate Level Frames}

Intermediate level frames have a more specialized focus than the grand theories and, as such, have the property that they can contribute in a more refined way to the 
design of particular curricular areas. In brief, intermediate level frames are located between the grand theories and the more local, domain-specific frames, the latter of which will be seen to deal with distinct mathematical concepts, procedures, or processes of mathematical reasoning. The multitude of intermediate level frames that are being applied to design research in mathematics education include, for example, Realistic Mathematics Education theory (Treffers 1987), the Theory of Didactical Situations (Brousseau 1997), the Anthropological Theory of the Didactic (Chevallard 1999), Lesson Study (Lewis 2002), Variation Theory (Runesson 2005), Conceptual Change Theory (van Dooren et al. 2013), and so on.

In general, intermediate level frames can be characterized by explicit principles/ heuristics/tools that can be applied to the design of tasks and task-sequences. Because these frames tend to be highly developed, they are often used in design as intention approaches. In addition, intermediate level frames can also be characterized according to whether their roots are primarily theoretical or whether they are based to a large extent on deep craft knowledge. An example of the former is the Theory of Didactical Situations and the latter, Lesson Study.

The Theory of Didactical Situations (TDS) (Brousseau 1997, 1998), an intermediate level theory that draws upon the grand theory of Piagetian cognitive development, can be characterized by its framing within a deep a priori analysis of the underlying mathematics of the topic to be learned, integrating the epistemology of the discipline, and supported by cognitive hypotheses related to the learning of the given topic. According to Ruthven et al. (2009), one of the central design tools provided by TDS is the adidactical situation, which mediates the development of students' mathematical knowledge through independent problem solving. The term adidactical within TDS refers specifically to that part of the activity "between the moment the student accepts the problem as if it were her own and the moment when she produces her answer, [a time when] the teacher refrains from interfering and suggesting the knowledge that she wants to see appear" (Brousseau 1997, p. 30). A situation includes both the task and the environment that is designed to provide for the adidactical activity of the student. According to the TDS frame, the adidactical situation tool furnishes guidelines as to: "the problem to be posed, the conditions under which it is to be solved, and the expected progression toward a strategy that is both valid and efficient" (Ruthven et al. 2009, p. 331). In addition to the adidactical situation tool, TDS-based design is also informed by a second design heuristic, that of the didactical variables tool. This supplementary design tool allows for choices regarding particular aspects of the main task and how it is to be carried out. Although certain modifications are made to those aspects of the task that are found to improve the learning potential of the situation (i.e., that students are more likely to learn what is intended), the initial design of the task is absolutely central to the TDS-framed design as intention process.

Lesson Study, an intermediate level frame typically associated with Japanese education (see, e.g., Fernandez and Yoshida 2004; Fujii 2015; Jacobs and Morita 2002), is a culturally-situated, collaborative, approach to design situated within the grand theory of socioculturalism and one where teachers with their deep, craft-based knowledge are pivotal to the process. It is a frame devoted as much to 
design as intention as it is to design as implementation. Lesson Study consists of the following phases: (1) collaboratively planning a research lesson; (2) seeing the research lesson in action; (3) discussing the research lesson; and optionally (4) revising the lesson; (5) teaching the new version of the lesson; and (6) sharing reflections on the new version of the lesson. Three design principles constitute the Lesson Study frame: (i) kyozaikenkyu, (ii) structured problem solving, and (iii) task evaluation. Kyozaikenkyu means literally "instructional materials research" and focuses on the detailed planning of the research lesson. The second principle, that of structured problem solving, involves, according to Stigler and Hiebert (1999), a single task and the following four specific phases: (i) teacher presenting the problem (donyu, 5-10 min), (ii) students working at solving the problem without the teacher's help (jiriki-kaiketsu, 10-20 min), (iii) comparing and discussing solution approaches (neriage, 10-20 min), and (iv) summing up by the teacher (matome, $5 \mathrm{~min}$ ). After the research lesson has been observed by other teachers, school administrators, and sometimes an outside expert, it is then discussed and evaluated in relation to its overall goals. This process of lesson evaluation, and in particular task evaluation, is considered a third design principle. The post-lesson discussion focuses to a large extent on the effects of the initial task design with respect to student thinking and learning. The teacher's thought-out key questioning receives much attention. Another of the main aspects discussed is whether the anticipated student solutions were in fact evoked by the task and its accompanying manipulative materials, or whether improvements in specific parts of the task design are warranted.

\subsubsection{Domain-Specific Frames}

In contrast to intermediate level frames whose characterizations do not specify any particular mathematical reasoning process or any particular mathematical content area, domain-specific frames for the design of tasks or task-sequences do specify particular reasoning processes (e.g., conjecturing, arguing, proving) or particular content (e.g., geometry, integer numbers, numerical concepts, algebraic techniques) or particular tools (e.g., computers, calculators, tablets; for further exposition of various task-design frames related directly to the integration of tools, see Leung and Bolite-Frant 2015). Task-design-research studies involving domain-specific frames typically draw upon past research findings in a given area, in addition to being situated within certain intermediate level, and more general grand-level, frameworks. As such, domain-specific frames for task design research tend to be more eclectic than their intermediate level counterparts.

Note that some researchers use the term "local theories" or "local frames" for what I am referring to here as domain-specific frames. In general, research designed with domain-specific frames can have the characteristics of both design as intention and design as implementation studies with their attention to, on the one hand, the theoretical underpinnings of the design of the tasks and the proposed instructional 
supports, and, on the other hand, the aim of further developing the theoretical domain-specific frame by means of the implementation process. Examples of studies on the use and development of domain-specific frames include, for instance, Prusak et al.'s (2013) research involving a domain-specific frame for fostering mathematical argumentation within geometric problem solving, Komatsu and Tsujiyama's (2013) frame for proof problems with diagrams, and Stephan and Akyuz's (2012, 2013) frame for the learning of integer concepts and operations. With the aim of elaborating further on the nature of domain-specific frames, I offer an example drawn from our team's research on algebra learning with technological tools.

\subsection{A Domain-Specific Frame for the CAS-Supported Co-emergence of Technique and Theory within the Activity of Algebraic Factorization}

In our past research on the use of $\mathrm{CAS}^{2}$ technology in algebra learning, we ${ }^{3}$ have carried out several studies with classes of Grade 10 students (16-year-olds), with each study involving multiple sets of CAS-supported task-sequences. In the paper by Kieran and Drijvers (2006), we reported on the classroom implementation of two of these task-sequences (see also Hitt and Kieran 2009), one of which is the focus of this section and which is herein presented with a detailed description of the domain-specific frame that underpinned its design.

\subsubsection{The Theoretical Underpinnings of the Design Study}

One of the two specific task-sequences described in the Kieran and Drijvers (2006) paper involved an elaboration of the factoring task of $x^{n}-1$, a task inspired by the earlier work of Mounier and Aldon (1996).

The design of the $x^{n}-1$ task-sequence, as was the case with the design of all of our algebra task-sequences, was situated within and drew upon aspects of the following intermediate level and domain-specific level frameworks, the entire combination of these specific frameworks constituting the domain-specific frame for our design study:

\footnotetext{
${ }^{2}$ A Computer Algebra System (CAS) is a software program that facilitates symbolic mathematics. The core functionality of a CAS is manipulation of mathematical expressions in symbolic form. ${ }^{3}$ Team members: C. Kieran, A. Boileau, D. Tanguay, and J. Guzmánł; also including at various times: F. Hitt, P. Drijvers, L. Saldanha, M. Artigue, A. Solares, and A. I. Sacristán. Website: profmath.uqam.ca/ APTE/TachesA.html
} 
- The intermediate level frameworks of:

- The Anthropological Theory of the Didactic (ATD) (Chevallard 1999) with its Task-Technique-Theory (TTT) tool,

- The Instrumental Approach to Tool Use with its dual Vygotskian and Piagetian roots (Artigue 2002; Vérillon and Rabardel 1995),

- Pólya's (1945/1957) mathematical problem-solving frame (especially the phase of "looking back", i.e., reflecting), and

- Didactical Engineering (Artigue 1992), the design-based frame with an emphasis on a priori mathematical and epistemological analyses for shaping not only the design of individual tasks but also their ordering;

- The domain-specific frames resulting from prior research involving:

- Algebraic activity (Kieran 1992, 2007) - in particular, Kieran's (2004) domain-specific model for conceptualizing such activity in terms of its generational, transformational, and global/meta-level aspects,

- Mathematical reasoning processes developed by means of teacher-student and student-student social interaction within collective classroom discussion (e.g., Herbel-Eisenmann and Cirillo 2009), and

- Tool-based activity with CAS technology for symbol manipulation in algebra (e.g., Artigue 1997; Lagrange 2002).

While all of these frameworks were included in various ways and to various extents within the design of the task-sequence and how it was projected to unfold, space constraints do not allow for specifying exactly where and how each frame was instantiated. But it can be noted, more generally, that in line with the ATD framework, which is an integral part of the Instrumental Approach to Tool Use frame and where the TTT tool is well characterized (see Artigue 2002), our focus was on the interplay between the technical and the conceptual, that is, on the techniques and theories that students develop while using technological tools and in social interaction. Crucial to the notion that conceptual understanding can co-emerge with technique, and in line with the Kieran (2004) model of algebraic activity, the transformational aspects of algebra (involving factoring, expanding, etc.) need to be linked - especially during their early phases of learning - to the global/meta-level activity of algebra (involving, e.g., noticing structure, generalizing, analyzing relationships, predicting, justifying, proving). As Lagrange (2003) has argued: "Technique plays an epistemic role by contributing to an understanding of the objects that it handles, particularly during its elaboration. It also serves as an object for conceptual reflection when compared with other techniques and when discussed with regard to consistency" (p. 271).

Emanating from the above frameworks that underpinned our research, the crafting of the multiple task-sequences involved the following five design principles:

- Integrate a dialectic between technical and theoretical activity within a predominantly exploratory, inquiry-based approach;

- Integrate the CAS as an epistemic motor for developing students' theoretical thinking and as a tool for generating and testing conjectures; 
- Interweave paper-and-pencil work with CAS activity with the aim of coordinating the technical and theoretical aspects of the mathematics;

- Include questions of a reflective nature where students write about how they are interpreting the content they are working on and eventually talk about and explain their ways of thinking;

- Integrate questions that call upon processes such as pattern seeking, looking for different ways of structuring a given expression, conjecturing, predicting, testing conjectures, and justifying.

The design of the particular task-sequence related to the factoring of $x^{n}-1$, because of its strong focus on generalization, also drew upon additional domain-specific frames related to the process of generalizing (e.g., Cañadas et al. 2007; Mason 1996) - frames that shaped the following three-phase sequence for the individual tasks we designed:

1. Seeing patterns in factors and moving toward a generalization;

2. Refining a generalization — with conjecturing and reconciling; and

3. Proving a generalization.

The first phase, which involved CAS as well as paper and pencil, linked students' past experience with factoring to the generalization that they would be working towards regarding the factoring of $x^{n}-1$. The beginning group of tasks was oriented towards noticing a particular regularity in the factored examples of the $x^{n}-1$ family of polynomials for positive integral values of $n$ and then justifying the form of these products. As is illustrated by the sample questions provided in Fig. 12.1, the tasks aimed at promoting an awareness of the presence of the factor $(x-1)$ in the given factored forms of the expressions $x^{2}-1, x^{3}-1$, and $x^{4}-1$. To promote generalization of the form $x^{n}-1=(x-1)\left(x^{n-1}+x^{n-2}+\cdots+x+1\right)$, students were then to be asked to judge the validity of the equality presented in Question 6 of Fig. 12.1. After students began to conjecture a general rule for the factorization of the $x^{n}-1$ family, they were to be requested to reflect on how they

1. Perform the indicated operations: $(x-1)(x+1) ;(x-1)\left(x^{2}+x+1\right)$.

2. Without doing any algebraic manipulation, anticipate the result of the following product $(x-1)\left(x^{3}+x^{2}+x+1\right)=$

3. Verify the above result using paper and pencil, and then using the calculator.

4. What do the following three expressions have in common? And, also, how do they differ? $(x-1)(x+1),(x-1)\left(x^{2}+x+1\right)$, and $(x-1)\left(x^{3}+x^{2}+x+1\right)$.

5. How do you explain the fact that when you multiply: i) the two binomials above, ii) the binomial with the trinomial above, and iii) the binomial with the quadrinomial above, you always obtain a binomial as the product?

6. Is your explanation valid for the following equality: $(x-1)\left(x^{134}+x^{133}+x^{132}+\ldots+x^{2}+x+1\right)=x^{135}-1$ ? Explain.

Fig. 12.1 Some of the initial tasks from the first phase of the $x^{n}-1$ task-sequence 
might express this conjecture by means of symbolic notation, using the symbol $n$ for the exponent, rather than specific integers.

The next phase of the task-sequence involved students' confronting the paper-and-pencil factorizations that they produced for $x^{n}-1$, for integer values of $n$ from 2 to 6 (and then from 7 to 13), with the completely factored forms produced by the CAS, and in reconciling these two factorizations (see Fig. 12.2).

An important aspect of this phase of the task-sequence involved reflecting on and forming conjectures (see Fig. 12.3) on the relations between particular expressions of the $x^{n}-1$ family and their completely factored forms.

The third phase of the task-sequence (see Fig. 12.4) focused on students' proving one of the conjectures that they had generated during the previous phase of the task-sequence.

In this activity each line of the table below must be filled in completely (all three cells), one row at a time. Start from the top row (the cells of the three columns) and work your way down. If, for a given row, the results in the left and middle columns differ, reconcile the two by using algebraic manipulations in the right hand column.

\begin{tabular}{|l|l|l||}
\hline $\begin{array}{l}\text { Factorization using } \\
\text { paper and pencil }\end{array}$ & $\begin{array}{l}\text { Result produced by the } \\
\text { FACTOR command }\end{array}$ & $\begin{array}{l}\text { Calculation to reconcile the two, } \\
\text { if necessary }\end{array}$ \\
\hline \hline$x^{2}-1=$ & & \\
\hline$x^{3}-1=$ & & \\
\hline$x^{4}-1=$ & & \\
\hline$x^{5}-1=$ & & \\
\hline$x^{6}-1=$ & & \\
\hline
\end{tabular}

Fig. 12.2 One of the factorization tasks from the second phase of the $x^{n}-1$ task-sequence

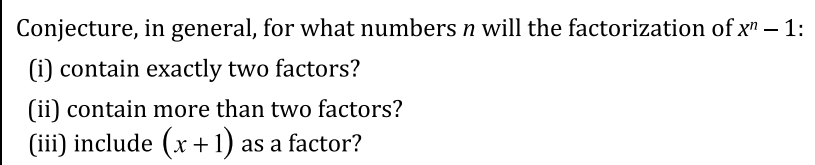

Fig. 12.3 A conjecturing task from the second phase of the $x^{n}-1$ task-sequence where students examine more closely the nature of the factors produced by the CAS

Prove that $(x+1)$ is always a factor of $x^{n}-1$ for even values of $n$.

Fig. 12.4 The proving task from the third phase of the $x^{n}-1$ task-sequence 
The nature of the students' reflections related to the proving task was to be revealed by having some of them present and explain their proofs at the board, and by encouraging classroom discussion, query, and reaction to the presented proofs. This and other instructional practice principles, which were fully described in the accompanying teacher guide that we designed, included the following:

- Allow enough time for students to grapple with and think through the given tasks (both individually and group-wise) before initiating collective discussion of this work;

- Have students present and explain their work at the board;

- Support students in presenting their work and in having them justify their thinking;

- Encourage classroom discussion, query, and reaction to work presented at the board; and

- Elicit students' thinking during collective discussions and encourage them to share their ideas, questions, and conjectures, rather than accepting quick and easy answers or rapidly giving them the answers.

Up to this point, the study could be characterized as primarily one of design as intention, with its rigorous attention to the initial formulation of the design by means of existing theoretical bases and their design principles, as well as the setting of instructional practice principles. However, we were also interested in the further development of theory by means of the implementation of the design study - the development of theory being a principal characteristic of design as implementation studies. We wanted to document the process by which the designed sequence was integrated into the classroom environment and focus on aspects that appeared to be especially crucial to the growth of learning. While the entire description of the design study constitutes its theoretical role, it is important that a design theory explain why designs work. In our case, the designed task-sequence - and the design study as a whole - was found to work especially well, not only because of the nature of the tasks in the sequence itself, but also because of two additional factors: the instructional practice of the participating teacher and the role played by the computing technology as a tool for thinking. An extract drawn from the process of classroom implementation, which encapsulates this dual aspect, now follows. It centers on the proving task presented above in Fig. 12.4.

\subsubsection{The Implementation of the Design Study}

The intermediate and domain-specific theoretical frames underpinning the study, in particular, the Task-Technique-Theory tool of the ATD framework, guided the analysis of the implementation process and allowed for the identification of students' going back-and-forth between theoretical thinking and technical growth (see Kieran and Drijvers 2006). However, the students' progress could not be completely accounted for without developing complementary theoretical 
explanations while analyzing the implementation process - theoretical explanations involving both the teacher and the technology.

After students had completed the first two phases of the $x^{n}-1$ task-sequence, they were faced with the proving segment: "Prove that $(x+1)$ is always a factor of $x^{n}-1$ for even values of $n$." It is noted that none of the students had had any prior experience with proving in algebra. They worked on this part of the task-sequence, mostly within small groups, for about $15 \mathrm{~min}$. Several of the students were using their CAS calculators; others were just talking about how they might approach the task and occasionally jotting down notes on paper. During that time, the teacher $(\mathrm{T})$ circulated and was heard to offer the following remark to a group of students - a remark that was in fact addressed to the whole class (see Kieran and Guzmán 2010, pp. 131-132):

T: See if you can prove this and not just state it, as some people have done so far (picking up one student's worksheet and reading it to the class): 'When $n$ is greater than or equal to $2,(x+1)$ is a factor because.' Let's see if we can go a little bit beyond that. Can you write down what you come up with.... Yeah, but you need more than just examples. ... You need to get something written down. ... Look, you need to think in order to answer this. This is the only hint I'm giving you, you need to think about where the $(x+1)$ comes from.

With the teacher's encouragement, the students began to move forward in the proving task. When he sensed that the majority of them had arrived at some form of a proof, he opened up a whole-class discussion, oriented around various students' sharing their work:

T: Ok, guys. Quite a lot of you got quite close in doing this. What I want you to do, and I've asked a couple of people who've done it in completely different ways, to see if they can put forward their explanation. I want you to be quiet, listen to their explanation, then we'll discuss it once they've got it done, once they've completed their little spiel, ok.

He invited selected students to come to the board, one at a time. The first "proof" by Paul revolved around the idea of 'difference of squares':

Paul: $\quad$ Ok. So, my theory is that whenever $x^{n}-1$ has an even value for $n$, if it's greater or equal to 2, that, one of the factors of that would be $x^{2}-1$, and since $x^{2}-1$ is always a factor of one of those, a factor of $x^{2}-1$ is $(x+1)$, so then $(x+1)$ is always a factor.

Student2: Could you say it again? [other students react all at once, making many comments]

Student3: Why don't you write it on the board?

T: Guys! Give him a chance.

Paul: $\quad$ You want me to write? [addressing the teacher]

T: Write down what you want to write down.

Student4: Can you talk at the same time? 
Paul proceeded to write down at the board what he had just stated orally. The teacher then asked: "Is everyone willing to accept his explanation?" While many seemed to agree with what Paul had proposed, a few voiced disagreement. One student, Dan, argued that, for example, $x^{12}-1$ did not have to be approached as a difference of squares; it could be factored in another way so as to end up with a factor that was a sum of cubes, $x^{3}+1$, which would in turn yield $(x+1)\left(x^{2}-x+1\right)$. However, Paul insisted that, just because $x^{12}-1$ could be factored in a different way, this did not contradict his original claim. After further class discussion, the teacher pointed out that, for Paul's proof to be complete, there needed to be a theoretical link connecting the two main lines of the proof (i.e., the $x^{n}-1$ line and the $x^{2}-1$ line): "Yes, we know we will get there eventually, but how do we know that we will eventually get there without doing all the actual factoring?" Paul's proof had a 'gap' in it.

The second approach to the proving problem was put forward by Janet. Janet's proof, which she and her partner Alexandra had together generated, was based on their earlier work on reconciling CAS factors with their paper-and-pencil factoring (for the tasks shown in Fig. 12.2). They had noticed that for even $n$ s, the number of terms in the second factor was always even. Janet argued, as she presented the proof at the board using $x^{8}-1$ as an example, that it would work for any even $n$ :

Janet: When $n$ is an even number

T: $\quad$ Write it on the board, show it on the board.

Janet: [she writes " $x^{8}-1$ " and below it: $\left.(x-1)\left(x^{7}+x^{6}+x^{5}+x^{4}+x^{3}+x^{2}+x+1\right)\right]$

T: $\quad$ Ok, listen 'cause this is interesting [addressed to the rest of the class], it's a completely different way of looking at it, to what most of you guys did. Ok, so explain it, Janet.

Janet: When $n$ is an even number [she points to the 8 in the $x^{8}-1$ that she has written], the number of terms in this bracket is even, which means they can be grouped and a factor is always $(x+1)$.

$\mathrm{T}$ : $\quad$ Can you show that?

Janet: [she groups the second factor as follows, $\left.x^{6}(x+1)+x^{4}(x+1)+x^{2}(x+1)+1(x+1)\right]$

T: Thanks Janet. Do we understand what she put out there?

Shortly after Janet had finished explaining her proof, the issue of Paul's proof came up once more. When Paul had presented his proof to the class, the implicit underlying argument was that when one begins with $x^{n}-1$ where $n$ is an even integer, and if one continually takes the even exponent and treats the binomial as a difference of squares, then one eventually arrives at $x^{2}-1$. To provoke the students, the teacher offered the following counter-example: "Just out of interest, what would happen if this was $x^{14}-1$ ? [he wrote $\left(x^{14}-1\right)$ under the $\left(x^{n}-1\right)$ ], to which a student easily responded: " $\left(x^{7}-1\right)$ times $\left(x^{7}+1\right)$." The teacher wrote at the board $\left(x^{14}-1\right)=\left(x^{7}-1\right)\left(x^{7}+1\right)$ and then wondered aloud: "Where does that leave your proof, Paul?" However, rather than leaving the class stymied, this question 
provided an opening for another student who had been conjecturing something new, based on his trial explorations with the CAS calculator:

Andrew: See, when it's a prime number, then the first part here is $x+1$ as a factor. ... From, like $x^{5}+1$ you get, $x^{4}-x^{3}+x^{2}-x+1$, like when you factor it on the calculator, that's what you get.

T: $\quad$ Ok.

Andrew: $\quad x+1$ times $x^{4}-x^{3}+x^{2}-x+1$.

T: $\quad$ Say it again Andrew [he is ready to write down Andrew's verbalizings at the board]

Andrew: When you factor $x^{10}-1$ on the calculator, you get $(x-1)$ times $(x+1)$ times $\left(x^{4}+x^{3}+x^{2}+x+1\right)$ times $\left(x^{4}-x^{3}+x^{2}-x+1\right)$.

T: $\quad$ Yeah [while completing the writing of Andrew's factorization at the board]. So, just go back a bit. That was these two together [tracing an arc joining $(x-1)$ and $\left.\left(x^{4}+x^{3}+x^{2}+x+1\right)\right]$ to give you the $x^{5}-1$.

Andrew: Yeah, and the next two would be $(x+1)$ and $\left(x^{4}-x^{3}+x^{2}-x+1\right)$.

T: $\quad$ So you're going into something that we haven't looked at in this class. You're setting up another hypothesis. What is your hypothesis?

Andrew: Well, that's what I was trying to get at. ... If the division by 2 gives an odd number, then it goes $(x+1)$.

T: $\quad$ So you're saying that, for the second hypothesis, something like this [he writes down $\left.\left(x^{5}+1\right)=(x+1)\left(x^{4}-x^{3}+x^{2}-x+1\right)\right]$. And you're saying that's true for all odd numbers?

Andrew: That's what I think.

T: $\quad$ So if we could prove this, then we've got it.

When Andrew had been working earlier on the second phase of the $x^{n}-1$ task-sequence, which had involved the reconciling of his paper-and-pencil factorings with the CAS factorings, the $x^{10}-1$ example had presented a surprise. He had first factored it with pencil and paper as $\left(x^{5}+1\right)\left(x^{5}-1\right)$, and then refactored the $\left(x^{5}-1\right)$ according to the newly-learned general rule for $x^{n}-1$, but had left the $\left(x^{5}+1\right)$ factor as is. But the CAS produced as its factored form for $x^{10}-1:(x-1)(x+1)\left(x^{4}+x^{3}+x^{2}+x+1\right)\left(x^{4}-x^{3}+x^{2}-x+1\right)$. Andrew noticed this additional factoring by the CAS, that is, that $x^{5}+1=(x+1)\left(x^{4}-x^{3}+x^{2}-x+1\right)$. He then remembered something similar from the previous task-sequence on the sum of cubes (done the week prior) and involving the factoring of $x^{3}+1$. At the same moment that he noticed the $x^{5}+1$ phenomenon, he mentioned to his desk-mate: "Isn't that how it works for the sum of cubes?" So, he then began to conjecture and test the more general rule: $x^{n}+1=(x+1)\left(x^{n-1}-x^{n-2}+\ldots-x+1\right)$, when $n$ is odd. Andrew, in presenting this emerging conjecture to the class, insisted that, even though "it does not seem to work for even $n \mathrm{~s}$, it is true for all odd numbers $n$, and $x+1$ would always be a factor of it." While Andrew never did come up with a generic proof for $x^{n}+1$ for odd $n \mathrm{~s}$, as had Janet for $x^{n}-1$ for even $n \mathrm{~s}$, his new conjecture provided a basis for handling the counter-example of $x^{14}-1$. In sum, Andrew's activity with the CAS was quite remarkable in that not only did he notice 
the pattern in the factoring of $x^{5}+1$, but also that he spontaneously connected it with what he remembered about the factoring of $x^{3}+1$, and that all of this led to generating a novel conjecture that he was able to test with his CAS calculator.

\subsubsection{Theorizing Resulting from the Implementation of the Proving Phase of the Design Study}

The proving phase of the design study — and so too the previous phases of the study in the same classroom - is noteworthy for at least two aspects. As has been illustrated, the roles played by the teacher and by the computing technology in the emergence and evolution of students' learning were striking. The teacher was one who worked very hard at encouraging his students to reflect, at giving them time to do so, at listening closely to their reflections, and at having them share their reflections with the rest of the class. His predisposition to such practice was related to the importance he ascribed to students' learning to think for themselves. One of the signs of this didactical stance on mathematical learning was the way in which he presented counter-examples to challenge students' thinking rather than immediately correcting them or giving the right answer. He aimed at having students develop their mathematical reasoning and critical thinking.

As the case of this teacher suggests, not only can listening to students support the development of students' thinking, it can also lead to new awarenesses and professional growth in the teacher. He mentioned on several occasions during the post-lesson interview how struck he was by the quality of the mathematical contributions of his students, contributions such as those by Janet and Andrew, which had evoked new mathematical insights within him, as well as within the students of his class. He was clearly a teacher who could learn from his students.

His disposition toward student reflection and student learning of mathematics, as well as his attitude with respect to his own learning, supported each other in a mutually intertwining manner. This is of interest from a theoretical perspective. It suggests firstly that the integration of novel materials and resources that have been designed to spur mathematical learning is more likely to be successful when the teachers who are doing the integrating are able to see that these resources are having a positive effect on their students' learning. Secondly, the novel materials and resources have a greater likelihood of producing this positive effect on student learning when the teacher doing the integrating engages in teaching practices that encourage student reflection and mathematical reasoning.

The second noteworthy aspect concerns the role of the CAS technology in the students' learning. To clarify, while the CAS technology was not initially created by its programming designers for pedagogical purposes but rather as a tool for doing mathematics, its integration into learning environments has been shown to lead students to explore their own novel conjectures and to allow for generating, testing, and improving conjectures. Ample evidence of this facet of CAS technology use was observed in Andrew's activity within our own design study. 
It would be hard to envisage him even noticing the phenomenon regarding the factorization of $x^{5}+1$, much less being able to formulate and test effectively his newly formed conjecture about the factors of $x^{n}+1$ for odd $n$ s in a pencil-and-paper environment. The role of the CAS calculator was crucial at this moment, and reminds us of a point made by Mason (2010): "Learning has taken place when people discern details, recognize relationships, and perceive properties not previously discerned through attending in fresh or distinct ways, and when they have fresh possibilities for action from which to choose" (p. 24). The CAS offered Andrew and the other students the "fresh possibilities for action" and allowed for the "discernment of details and the recognition of relationships."

But the CAS technology also played an important role for the teacher and for his practice. The teacher remarked at the completion of the $x^{n}-1$ task-sequence that the presence of the technology changes the nature of the questions that can be asked of students, and thus the kind of mathematical reflection they engage in. While the tasks themselves were, according to the teacher, a crucial component of the students' learning and pushed them beyond what is normally asked of them in their mathematics program, it must be added that the actual design of the tasks was set up in such a way as to work hand-in-hand with the affordances of the technology. In fact, the first two phases of the $x^{n}-1$ task-sequence, which were foundational to the proving part of the activity, could not have been managed without the CAS. The teacher added that the interaction with the CAS calculators actually "made the students think more about the algebraic processes that they knew how to do, in particular, to think about the way in which they understood this material-basically the meta-cognition kind of idea of thinking about the process you're going through yourself. That's something we don't do enough of in mathematics." Before the unfolding of the design study in his own classroom, he never imagined the impact of this technology on his students' mathematical learning, and thus on his own learning of what his students could accomplish. In his reflecting on his students' reflections, his vision of what his students could learn mathematically had changed, as well as his awareness of the role within the learning process that CAS technology can play when situated within the context of suitably demanding task-sequences.

\subsection{Concluding Remarks}

In this chapter, I have examined the design process and task design from the standpoint of the frameworks and principles that are reflective of the historical development of design-oriented theorizing research in mathematics education. The particular perspective that was used was that of grand, intermediate, and domain-specific levels of frames - a perspective illustrating the ways in which frames and task design are related. An example was provided of a domain-specific frame for a design study focusing on the processes of conjecturing, generalizing, and proving within the algebraic content area of factoring technique and involving the CAS calculator tool. This example embodied the two dimensions of (i) design 
as intention, with its description of the initial formulation of the design that was underpinned by specific frameworks and principles, and (ii) design as implementation with its description of the process by which the designed sequence was integrated into the classroom environment - a process that specified the tasks, the kinds of classroom discussion that were encouraged, the tools that were provided, and the practical means by which the teacher orchestrated relations among these elements. While the entire description of the initial formulation and implementation of the design study constitutes the development of the theoretical role played by such studies, specific theoretical products resulting from this design study included the following:

- the emergence of students' theoretical notions within the further growth of their technical knowledge in algebra,

- the nature of the teacher's classroom practice, which fostered the co-emergence of algebraic theory and technique,

- the students' capacity to notice theory-inducing phenomena in the outputs provided by the CAS technology tool, and

- the quality of the teacher's reflections on his students' learning that were provoked by the designed task-with-technology environment and which in turn constituted a form of professional development for him.

In sum, the domain-specific frame that was used for the design study, and its further elaboration that was the result of the study, is one that theorized the co-emergence of algebraic conceptual and technical knowledge in a technology-supported, task-based classroom environment that constituted learning for both students and teacher. Its success depended to a great extent upon the specific instructional practice of the participating teacher, as well as the affordances of the CAS technology as a tool to spur thinking. To conclude, the frame is one that can serve as a basis for further design research in the recursive process of domain-specific-frame-development in the particular content area of algebra.

\section{References}

Ainley, J., \& Pratt, D. (2005). The significance of task design in mathematics education: Examples from proportional reasoning. In H. L. Chick \& J. L. Vincent (Eds.), Proceedings of the 29th conference of the international group for the psychology of mathematics education (Vol. 1, pp. 103-108). Melbourne: PME.

Artigue, M. (1992). Didactical engineering. In R. Douady \& A. Mercier (Eds.), Recherches en Didactique des Mathématiques, Selected papers (pp. 41-70). Grenoble: La Pensée Sauvage.

Artigue, M. (1997). Le Logiciel 'Derive' comme révélateur de phénomènes didactiques liés à l'utilisation d'environnements informatiques pour l'apprentissage [Derive software, a revealer of didactical phenomena related to the use of computer learning environments]. Educational Studies in Mathematics, 33, 133-169.

Artigue, M. (2002). Learning mathematics in a CAS environment: The genesis of a reflection about instrumentation and the dialectics between technical and conceptual work. International Journal of Computers for Mathematical Learning, 7, 245-274. 
Artigue, M. (2009). Didactical design in mathematics education. In C. Winslow (Ed.), Nordic research in mathematics education: Proceedings from NORMA08 in Copenhagen (pp. 7-16). Rotterdam: Sense Publishers.

Bell, A. W. (1979). Research on teaching methods in secondary mathematics. In D. Tall (Ed.), Proceedings of the third conference of the international group for the psychology of mathematics education (pp. 4-12). Warwick: PME.

Bell, A. (1993). Guest editorial. Educational Studies in Mathematics, 24, 1-4.

Brousseau, G. (1997). Theory of didactical situations in mathematics (N. Balacheff, M. Cooper, R. Sutherland, \& V. Warfield, Eds. \& Trans.). Dordrecht: Kluwer Academic.

Brousseau, G. (1998). Théorie des situations didactiques [Theory of didactical situations] (N. Balacheff, M. Cooper, R. Sutherland, \& V. Warfield, Eds.). Grenoble: La Pensée Sauvage.

Brown, A. L. (1992). Design experiments: Theoretical and methodological challenges in creating complex interventions in classroom settings. Journal of the Learning Sciences, 2(2), 141-178.

Cañadas, M. C., Deulofeu, J., Figueiras, L., Reid, D. A., \& Yevdokimov, O. (2007). The conjecturing process: Perspectives in theory and implications in practice. Journal of Teaching and Learning, 5(1), 55-72.

Chevallard, Y. (1999). L'analyse des pratiques enseignantes en théorie anthropologique du didactique [The analysis of teaching practice in the anthropological theory of the didactic]. Recherches en Didactique des Mathématiques, 19, 221-266.

Cobb, P. (2007). Putting philosophy to work: Coping with multiple theoretical perspectives. In F. K. Lester Jr. (Ed.), Second handbook of research on mathematics teaching and learning (pp. 3-67). Charlotte: Information Age.

Cobb, P., Confrey, J., diSessa, A., Lehrer, R., \& Schauble, L. (2003). Design experiments in educational research. Educational Researcher, 32(1), 9-13.

Collins, A., Joseph, D., \& Bielaczyc, K. (2004). Design research: Theoretical and methodological issues. Journal of the Learning Sciences, 13, 15-42.

Fernandez, C., \& Yoshida, M. (2004). Lesson study: A Japanese approach to improving mathematics teaching and learning. Mahwah: Lawrence Erlbaum Associates.

Freudenthal, H. (1979). How does reflective thinking develop? In D. Tall (Ed.), Proceedings of the third conference of the international group for the psychology of mathematics education (pp. 92-107). Warwick: PME.

Fujii, T. (2015). The critical role of task design in Lesson Study. In A. Watson \& M. Ohtani (Eds.), Task design in mathematics education: An ICMI Study 22 (pp. 273-286). New York: Springer.

Gagné, R. M. (1965). The conditions of learning. New York: Holt, Rinehart \& Winston.

Glaser, R. (1976). Components of a psychology of instruction: Toward a science of design. Review of Educational Research, 46(1), 1-24.

Gravemeijer, K., \& Cobb, P. (2006). Design research from a learning design perspective. In J. van den Akker, K. Gravemeijer, S. McKenney, \& N. Nieveen (Eds.), Educational design research (pp. 45-85). http://www.fisme.science.uu.nl/publicaties/literatuur/EducationalDesignResearch. pdf.

Herbel-Eisenmann, B., \& Cirillo, M. (Eds.). (2009). Promoting purposeful discourse. Teacher research in mathematics classrooms. Reston: National Council of Teachers of Mathematics.

Hitt, F., \& Kieran, C. (2009). Constructing knowledge via a peer interaction in a CAS environment with tasks designed from a Task-Technique-Theory perspective. International Journal of Computers for Mathematical Learning, 14, 121-152.

Jacobs, J. K., \& Morita, E. (2002). Japanese and American teachers' evaluations of videotaped mathematics lessons. Journal for Research in Mathematics Education, 33, 154-175.

Johnson, D. C. (1980). The research process. In R. J. Shumway (Ed.), Research in mathematics education (pp. 29-46). Reston: National Council of Teachers of Mathematics.

Kelly, A. E., Lesh, R. A., \& Baek, J. Y. (Eds.). (2008). Handbook of design research methods in education. London: Routledge.

Kieran, C. (1992). The learning and teaching of school algebra. In D. A. Grouws (Ed.), Handbook of research on mathematics teaching and learning (pp. 390-419). New York: Macmillan. 
Kieran, C. (2004). The core of algebra: Reflection on its main activities. In K. Stacey, H. Chick, \& M. Kendal (Eds.), The future of the teaching and learning of algebra: The 12th ICMI Study (pp. 21-33). Dordrecht: Kluwer Academic Publishers.

Kieran, C. (2007). Learning and teaching algebra at the middle school through college levels: Building meaning for symbols and their manipulation. In F. K. Lester Jr. (Ed.), Second handbook of research on mathematics teaching and learning (pp. 707-762). Greenwich: Information Age.

Kieran, C. (2017). Task design in mathematics education: Frameworks and exemplars. In S. Oesterle, D. Allan, \& J. Holm (Eds.), Proceedings of the 2016 annual meeting of the Canadian mathematics education study group (pp. 45-66). Kingston: CMESG.

Kieran, C., \& Drijvers, P. (2006). The co-emergence of machine techniques, paper-and-pencil techniques, and theoretical reflection: A study of CAS use in secondary school algebra. International Journal of Computers for Mathematical Learning, 11, 205-263.

Kieran, C., \& Guzmán, J. (2010). Role of task and technology in provoking teacher change: A case of proofs and proving in high school algebra. In R. Leikin \& R. Zazkis (Eds.), Learning through teaching mathematics: Development of teachers' knowledge and expertise in practice (pp. 127-152). New York: Springer.

Kieran, C., Doorman, M., \& Ohtani, M. (2015). Frameworks and principles for task design. In A. Watson \& M. Ohtani (Eds.), Task design in mathematics education: An ICMI Study 22 (pp. 19-81). New York: Springer.

Kilpatrick, J. (1992). A history of research in mathematics education. In D. A. Grouws (Ed.), Handbook of research on mathematics teaching and learning (pp. 3-38). New York: Macmillan.

Komatsu, K., \& Tsujiyama, Y. (2013). Principles of task design to foster proofs and refutations in mathematical learning: Proof problem with diagram. In C. Margolinas (Ed.), Task design in mathematics education: Proceedings of ICMI Study 22 (pp. 471-480). https://hal.archivesouvertes.fr/hal-00834054.

Lagrange, J.-B. (2002). Étudier les mathématiques avec les calculatrices symboliques. Quelle place pour les techniques? [Studying mathematics with symbolic calculators. What place is there for techniques?] In D. Guin \& L. Trouche (Eds), Calculatrices symboliques. Transformer un outil en un instrument du travail mathématique: un problème didactique (pp. 151-185). Grenoble: La Pensée Sauvage.

Lagrange, J.-B. (2003). Learning techniques and concepts using CAS: A practical and theoretical reflection. In J. T. Fey (Ed.), Computer algebra systems in secondary school mathematics education (pp. 269-283). Reston: National Council of Teachers of Mathematics.

Lerman, S., Xu, G., \& Tsatsaroni, A. (2002). Developing theories of mathematics education research: The ESM story. Educational Studies in Mathematics, 51, 23-40.

Lesh, R. A. (2002). Research design in mathematics education: Focusing on design experiments. In L. English (Ed.), Handbook of international research in mathematics education (pp. 27-50). Hillsdale: Lawrence Erlbaum Associates.

Leung, A., \& Bolite-Frant, J. (2015). Designing mathematics tasks: The role of tools. In A. Watson \& M. Ohtani (Eds.), Task design in mathematics education: An ICMI Study 22 (pp. 191-225). New York: Springer.

Lewis, C. (2002). Lesson study: A handbook of teacher-led instructional change. Philadelphia: Research for Better Schools.

Mason, J. (1996). Expressing generality and roots of algebra. In N. Bednarz, C. Kieran, \& L. F. Lee (Eds.), Approaches to algebra: Perspectives for research and teaching (pp. 85-86). Dordrecht: Kluwer Academic.

Mason, J. (2010). Attention and intention in learning about teaching through teaching. In R. Leikin \& R. Zazkis (Eds.), Learning through teaching mathematics: Development of teachers' knowledge and expertise in practice (pp. 23-47). New York: Springer.

Mounier, G., \& Aldon, G. (1996). A problem story: factorisations of $x^{n}-1$. International DERIVE Journal, 3, 51-61.

Piaget, J. (1971). Genetic epistemology. New York: W. W. Norton. 
Pólya, G. (1945/1957). How to solve it: A new aspect of mathematical method. Princeton: Princeton University Press.

Prediger, S., Bikner-Ahsbahs, A., \& Arzarello, F. (2008). Networking strategies and methods for connecting theoretical approaches: First steps towards a conceptual framework. ZDM: The International Journal on Mathematics Education, 40, 165-178.

Prusak, N., Hershkowitz, R., \& Schwarz, B. B. (2013). Conceptual learning in a principled design problem solving environment. Research in Mathematics Education, 15(3), 266-285. https:// doi.org/10.1080/14794802.2013.836379.

Runesson, U. (2005). Beyond discourse and interaction. Variation: A critical aspect for teaching and learning mathematics. The Cambridge Journal of Education, 35(1), 69-87.

Ruthven, K., Laborde, C., Leach, J., \& Tiberghien, A. (2009). Design tools in didactical research: Instrumenting the epistemological and the cognitive aspects of the design of teaching sequences. Educational Researcher, 38, 329-342.

Simon, H. A. (1969). The sciences of the artificial. Cambridge: MIT Press.

Stephan, M., \& Akyuz, D. (2012). A proposed instructional theory for integer addition and subtraction. Journal for Research in Mathematics Education, 43, 428-464.

Stephan, M., \& Akyuz, D. (2013). An instructional design collaborative in one middle school. In C. Margolinas (Ed.), Task design in mathematics education: Proceedings of ICMI Study 22 (pp. 509-518). https://hal.archives-ouvertes.fr/hal-00834054.

Stigler, J. W., \& Hiebert, J. (1999). The teaching gap. New York: Free Press.

Treffers, A. (1987). Three dimensions: A model of goal and theory description in mathematics instruction - The Wiskobas Project. Dordrecht: D. Reidel.

Van Dooren, W., Vamvakoussi, X., \& Verschaffel, L. (2013). Mind the gap-Task design principles to achieve conceptual change in rational number understanding. In C. Margolinas (Ed.), Task design in mathematics education: Proceedings of ICMI Study 22 (pp. 519-527). https://hal.archives-ouvertes.fr/hal-00834054.

Vérillon, P., \& Rabardel, P. (1995). Cognition and artifacts: A contribution to the study of thought in relation to instrumented activity. European Journal of Psychology of Education, 10, 77-103.

Watson, A., et al. (2013). Introduction. In C. Margolinas (Ed.), Task design in mathematics education: Proceedings of ICMI Study 22 (pp. 7-13). https://hal.archives-ouvertes.fr/hal00834054.

Watson, A., \& Ohtani, M. (Eds.). (2015). Task design in mathematics education: An ICMI Study 22. New York: Springer.

Wittmann, E. (1984). Teaching units as the integrating core of mathematics education. Educational Studies in Mathematics, 15, 25-36.

Wittmann, E. Ch. (1995). Mathematics education as a 'design science'. Educational Studies in Mathematics, 29, 355-374.

Open Access This chapter is licensed under the terms of the Creative Commons Attribution 4.0 International License (http://creativecommons.org/licenses/by/4.0/), which permits use, sharing, adaptation, distribution and reproduction in any medium or format, as long as you give appropriate credit to the original author(s) and the source, provide a link to the Creative Commons license and indicate if changes were made.

The images or other third party material in this chapter are included in the chapter's Creative Commons license, unless indicated otherwise in a credit line to the material. If material is not included in the chapter's Creative Commons license and your intended use is not permitted by statutory regulation or exceeds the permitted use, you will need to obtain permission directly from the copyright holder.

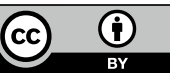

